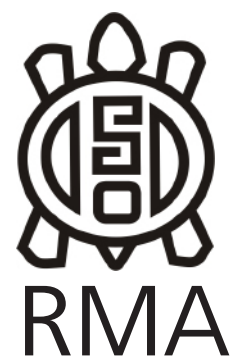

Dossier

\title{
Fibras animales arqueológicas. Estudio de su estructura física celular
}

\author{
María del Carmen Reigadas* \\ * Instituto Nacional de Antropología y Pensamiento Latinoamericano (INAPL), \\ E-mail: mcreigadas@fibertel.com.ar
}

\begin{abstract}
Resumen
El análisis microscópico de la morfología de fibras animales se ha empleado conjuntamente con otras líneas de evidencia, brindando información taxonómica útil para reconstruir posibles escenarios que den cuenta de las estrategias implementadas por las sociedades cazadoras- recolectoras y/ o productoras, en vistas a la explotación y aprovechamiento de los recursos animales.

En esta oportunidad y en el marco de la vía mencionada, se presenta como complemento de los resultados obtenidos a partir de las variables cualitativas y cuantitativas tales como grosor, médula, tipo de fibra y color, el avance realizado en el estudio de la corteza, estructura no contemplada hasta el presente. Se evalúa a partir de la información generada su relevancia en la búsqueda de indicadores interespecíficos.

El análisis fue realizado en muestras correspondientes al nivel 4 del sitio Cueva Salamanca $1(7500+60$ AP [Beta 178223]) (Pintar 2004) y nivel 264 de Quebrada Seca 3 (Cal. 3684- 4226 AC 1s) (Aschero et al. 1993-94), ambos localizados en la puna meridional (Antofagasta de la Sierra, Argentina) de las cuales ya se disponen designaciones taxonómicas obtenidas por análisis morfológico.
\end{abstract}

Palabras clave: recursos; fauna; fibras; características celulares; taxonomía.

Archaeological animal fibres. Study of their physical cellular structure

\begin{abstract}
Microscopic analysis of the morphology of animal fibers has been used in conjunction with other lines of evidence, providing useful taxonomic information to reconstruct scenarios that account for the strategies implemented by hunter-gatherers and producers, in view of the use of animal resources.

Here, the advance made in the study of cortical cells is offered as a complement to results obtained from qualitative and quantitative variables such as thickness, medulla, fiber type and color. The information gained is used to evaluate the relevance in the search of interspecific indicators.

The analysis was performed on samples corresponding to level 4 from Cueva Salamanca 1 (7500 \pm 60 BP Beta 178223) (Pintar 2004) and level 4 from Quebrada Seca 3 (Cal. 3684 to 4226 1s) Aschero et al. 1993- 94), both in the southern Puna (Antofagasta de la Sierra, Argentina) and of which taxonomic designations have already been obtained by morphological analysis.
\end{abstract}

Kewords: resources; fauna; fiber; cell characteristics; taxonomy.

\section{Objetivos y fundamentos}

El trabajo que aquí se presenta atiende a dos objetivos. En primer lugar, la necesidad de establecer controles para los datos ya generados vía análisis morfológico de fibras y composición de mantos y en segundo término, explorar nuevas variables incorporando el análisis de la corteza. La meta es establecer nuevos indicadores interespecíficos que favorezcan aproximaciones taxonómicas que den cuenta de los modos de explotación de la fauna, especialmente camélidos, durante el Holoceno en el noroeste de nuestro territorio.

Estudios efectuados en la estructura celular de las fibras de camélidos actuales (Wildman 1954; Tucker et al. 1988), permiten pensar que las variaciones observadas en la estructura interna de las fibras, se correlacionan con las variaciones de los parámetros obtenidos para la morfología de las mismas, siendo esta idea el sustento del estudio de prueba realizado en material arqueológico.

\section{Valoración de la variable corteza}

Durante el desarrollo embrionario células de la epidermis invaden la dermis para constituir glándulas sudoríparas y folículos pilosos que segregan pelos, los cuales distinguen a los mamíferos de los otros vertebrados. Se reconocen dos clases de folículos organizados en

Recibido 23-04-2012. Recibido con correcciones 23-07-2012. Aceptado 06-10-2012 
grupos como responsables de la producción de fibras gruesas y finas. Estos grupos son identificados como primarios y secundarios y su número está determinado genéticamente. La mayoría de los mamíferos poseen este bimanto o doble capa de fibras: unas más cortas y delgadas (lanilla), y otra de fibras más gruesas y largas (pelos), pero sus parámetros varían según las especies consideradas (Frank y Amuchástegui 1993). Por este motivo, el estudio de los folículos y morfología de las fibras resulta de valor para la determinación taxonómica. Asimismo, las fibras están compuestas transversalmente por una capa externa o cutícula, que conforma diversos patrones de escamas y una interna o corteza y algunas tienen una tercera estructura o médula central (Vázquez et al. 2000, Carpio 1991)

En base a fibras animales procedentes de diversos sitios arqueológicos del NOA, hemos realizado su estudio microscópico, tomando en cuenta tanto a las características intrínsecas, extrínsecas como a la estructura interna de las mismas. El análisis ha incluido la observación de variables cualitativas como color y cuantitativas, tales como grosor (diámetro en $\mu$ ), tipo de fibra (primariassecundarias), composición del manto (relación fibras $\mathrm{S} / \mathrm{P}$ ) y estrangulamientos/ quebraduras; para médula: grosor (diámetro en $\mu$ ), tipo (esponjosa, uniseriada, otras), distribución (ausente, fragmentaria, discontinua, continua) y medulación (Índice de medulación o IM, Porcentaje de medulación total o PMT) (Reigadas 1992, 2001, 2008).

En esta oportunidad se incluye en el estudio de la estructura interna, el estudio de la corteza (presencia y disposición de las células que componen la matriz), que constituye el cuerpo de las fibras. Al corte transversal de las mismas, las células de la corteza muestran una forma poligonal y a diferencia de las escamas de la cutícula (capa externa), están dispuestas verticalmente en forma de fibrillas longitudinales, con residuo nuclear en su parte central.

El examen microscópico transversal de las fibras en microscopio electrónico de transmisión (MET), permite distinguir el cortex (capa celular). En ella hay dos regiones definidas; el orthocortex y el paracortex. Por su composición, densidad, elasticidad, fijación de colorantes (Fraser et al. 1972) y apariencia al microscopio electrónico, se distinguen dos tipos de células corticales: orthocortex (basófilo, poco denso, blando, rico en proteínas con bajo contenido en azufre y con gran capacidad de fijación de colorantes) y paracortex (más denso, menos elástico, con elevado contenido en proteínas ricas en azufre y con escasa capacidad de fijación de colorantes). En cuanto a la disposición de los tipos de células se observan diferencias interespecíficas. En ovinos se presentan con una disposición bilateral enlazada; en caprinos (mohair), solo hay presencia de ortocortex mientras que en caprinos (cashmere) se observa una disposición concéntrica (ortocortex en el centro rodeado de paracortex) (Carpio 1991).
Satlow en el año 1965, reporta corteza bilateral para alpaca en base a observaciones realizadas en microscopio óptico. Por el contrario, diversos investigadores (Tucker et al. 1988; Tucker et al. 1990) en base a observaciones en MET, han reportado para guanaco y vicuña una disposición bilateral, más obvia en guanaco, y para llama una disposición indiferenciada, siendo estas variaciones de sumo interés por los objetivos mencionados.

\section{Procedencia de los materiales}

\section{Contexto arqueológico}

El Departamento de Antofagasta de la Sierra (Provincia de (atamarca) forma parte del desierto de altura denominado Puna de Atacama. Se localiza en el sector correspondiente a la puna meridional argentina $\left(22^{\circ}\right.$ y $27^{\circ}$ de latitud sur y $65^{\circ} 10^{\prime}$ y $68^{\circ} 50^{\prime}$ de longitud oeste) en la denominada puna salada con condiciones de aridez severas.

Se observan en el área tres tipos de sectores diferenciados ecológicamente: el fondo de la cuenca, los sectores intermedios y las quebradas altas.

Tomando como punto de partida la diversidad de líneas independientes (ambientales (Tchilinguirián et al. 2007), demográficas (Pintar 2011), tecnológicas (Pintar 2009; Martínez 2007), que dan cuenta de un proceso de cambio en Antofagasta de la Sierra, este trabajo aporta a la búsqueda y profundización de la información arqueofaunística que sustenta este desarrollo en el área de la puna meridional, que conlleva un proceso de intensificación con los recursos faunísticos, especialmente con los camélidos (Mondini y Elkin 2006; Reigadas 2008; Martinez et al. 2010; Reigadas y Mondini 2011; Mondini et al. 2011, entre otros).

Para la región se han establecido cambios climáticos y ambientales. Hacia los 8500 AP un aumento de la temperatura y aridez, proceso que se intensifica entre los 6300 y 3900 AP (Tchilinguirián et al. 2007). Esta situación para el norte de Chile se traduce en el abandono poblacional de áreas previamente ocupadas. A diferencia de ello, el registro arqueológico en Antofagasta de la Sierra, marca la permanencia de los grupos humanos en forma continua, pero con cambios sustanciales en diversos planos.

Diversas evidencias para el área de Antofagasta de la Sierra ubican para inicios del Holoceno las primeras ocupaciones de cazadores recolectores, con una economía basada fundamentalmente en la caza. Hacia el Holoceno Medio y Tardío, a partir de cambios en la estructura intrasitio (Aschero et al. 1993-1994), en el repertorio tecnológico (Pintar 1996), cambios producidos en la movilidad de las bandas (Pintar 2008), modificaciones en la territorialidad de los camélidos, en el tamaño corporal (Mengoni 


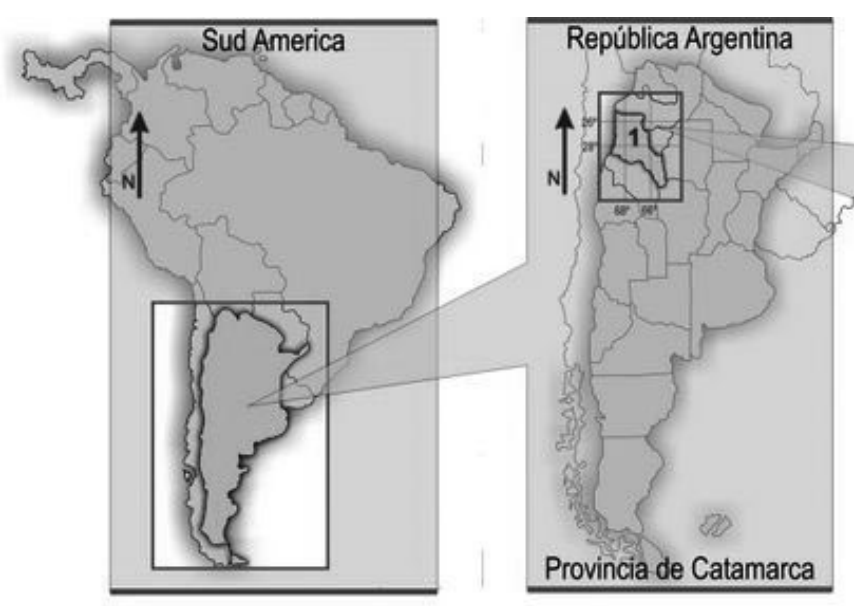

Figura 1. Localización de los sitios arqueológicos.

Figure 1. Location of archaeological sites.

y Yacobaccio 2006) y la composición de sus mantos (Reigadas 2001, 2006), se sugieren modificaciones en las estrategias del aprovechamiento del ambiente y una intensificación en la relación con los recursos animales (Olivera y Elkin 1994, Mondini y Elkin 2006).

Finalmente, se propone hacia el 3000 AP la consolidación de grupos con mayor sedentarismo, que conformarían en contextos más tardíos, en aldeas de fondo de valle y puestos de caza y pastoreo en quebradas altas, un sistema productivo basado en el manejo de la especie Lama glama con componentes agrícolas en diferentes escalas Olivera y Vigliani 200- 2002)

Las fibras analizadas provienen de los sitios Quebrada Seca 3 y Cueva Salamanca 1 (Figura 1).

El sitio Quebrada Seca 3 (QS3) se localiza en el sector de quebradas altas, en la subárea que comprende la zona ubicada al este de la confluencia de las Quebradas Seca y Real Grande, las que desembocan en la del río Pitas. El sitio es un alero ubicado a $4100 \mathrm{msnm}$ en la margen sur de la vega de la Quebrada homónima, a los $67^{\circ} 25^{\prime}$ Longitud $\mathrm{O}$ y $26^{\circ} 5^{\prime}$ Latitud S.

Las excavaciones han puesto en evidencia una serie de niveles de ocupación estratificados sin hallazgos cerámicos. El contexto se compone de restos vegetales, restos óseos, gran cantidad de material lítico, artefactos de madera y hueso, abundancia de vellones, cestería y pigmentos. Se han diferenciado 4 unidades estratigráficas principales: capa 0, 1, 2a y 2b, donde se pudieron detectar varios niveles de ocupación humana (inferiores, intermedios y superiores) con fechados radiocarbónicos (sin cal.) que van desde el $2480 \pm 60$ (LP 278) para la capa 2a hasta el $9050 \pm 90$ AP (Beta 59930) para la capa 2b19 (Elkin 1996).

El sitio provee evidencia humana temprana y continua para el sector de la puna meridional argentina desde comienzos del Holoceno, inclusive durante el Holoceno

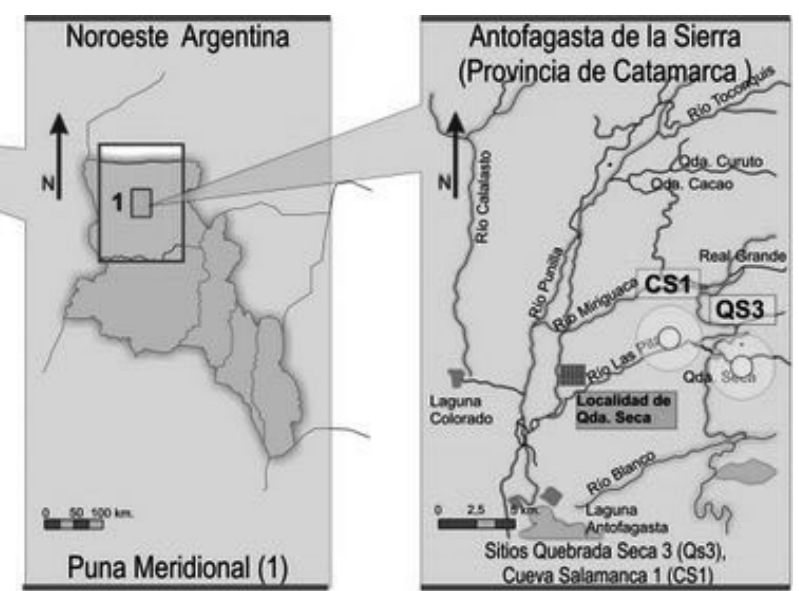

medio, con las condiciones de aridez para entonces establecidas. Las variaciones observadas en los conjuntos líticos de este sitio sugieren que: 1) durante las ocupaciones tempranas, el sitio podría haber sido base de cazadores con una alta movilidad residencial; (2) en los niveles medios, desde el 7760 \pm 80 AP (no cal.) Beta 77746, una estación de caza y reemplazo del equipo instrumental, con ocupación efímera del sitio y (3) en los niveles tardíos, hacia el 4410 160 AP (no cal.) UGA 8327, un sitio con reocupaciones periódicas, tal vez un "puesto" (Aschero et al. 1993-1994).

En este sitio se han efectuado estudios faunísticos y se dispone de resultados taxonómicos vía huesos, dientes y morfología de fibras. Se efectuaron asignaciones a Vicugna vicugna y Lama guanicoe, Rodentia y Cervidae. El análisis osteométrico ha permitido establecer dos grupos de tamaño de camélidos adultos, correspondiendo los especimenes más pequeños a vicuñas y los más grandes a guanacos. La presencia de vicuña se constata además a partir de incisivos. Si consideramos solamente los indicadores osteométricos y dentarios para este contexto faunístico, vemos que el fenotipo de los camélidos se mantiene constante dentro de los patrones silvestres (Elkin 1996, Mondini 2003). Por el contrario, si sumamos las características morfológicas de los vellones, además de las formas silvestres, observamos la aparición de un patrón de manto homologable al de llama desde los niveles tempranos de la secuencia, situación discutida en diversos trabajos (Reigadas 2001, 2006, 2008; Mengoni y Yacobaccio 2006; Mondini y Elkin 2006). De interés para los niveles superiores es la aparición muestras asignadas a patrón llama de colores blancos y teñidos en rojo y su utilización en cordeles.

Las muestras seleccionadas para el estudio de corteza corresponden a 20 fibras de una muestra de color blanco, procedentes del nivel 2b4 (Cal. 3684- 4226 AC 1s), por

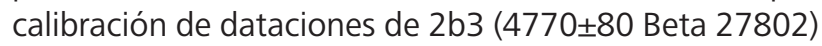
y 2 b5 (5380 70 Beta 59927) según el método Seattle/ Groningen (Aschero et al. 1993-94, Hocsman 2002) que fue asignada por estudio morfológico a patrón llama.

Otro de los sectores ecológicos es el intermedio, que 
se ubica en altitudes entre 3550 y 3800 msnm, con predominio de unidades vegetacionales correspondientes a la subunidad prepuneña y puneña. La Cueva Salamanca 1 (CS1) se encuentra en este sector, a los $26^{\circ} 01^{\prime} 22^{\prime \prime} \mathrm{S}$, $67^{\circ} 15^{\prime} 23^{\prime \prime}$ O y a 3560 msnm en un farallón ignimbrítico en la margen izquierda del río Las Pitas.

Sobre la base de lo estudiado para la Cueva Salamanca 1, Pintar (2004) define para los niveles correspondientes al Holoceno Medio (niveles 2 a 5) una ocupación más duradera con puntas de proyectil de morfología similar a aquellas de las ocupaciones medias del sitio Quebrada Seca 3, con presencia de una mano de moler con importante desgaste y la posible existencia de una pirca.

Los estudios faunísticos están en proceso y se dispone de resultados taxonómicos vía huesos para los niveles 2, 6, 7 y 10 y vía morfología de fibras para los niveles $1,2,4,5$, 7 y 10. Estos últimos estudios han dado como resultado hasta el momento presencia exclusiva de camélidos silvestres, en sus dos formas, Lama guanicoe y Vicugna vicugna, concordante con los resultados osteométricos disponibles (Mondini et al. 2011).

La muestra seleccionada en este caso corresponde al nivel 4 (7500 + 60 AP Beta 178223) (Pintar 2004) y fue asignada a camélido silvestre, específicamente guanaco.

Finalmente, los sitios mencionados cuentan con ocupaciones de grupos de cazadores-recolectores que abarcan distintos momentos de su evolución en el área. Ofrecen una variada gama de información para la comprensión de las diversas adaptaciones cazadorasrecolectoras en ecosistemas de altura, de su trayectoria evolutiva con los camélidos y para la búsqueda de indicadores que den cuenta de la intensificación en la relación del hombre con este recurso.

\section{Prueba de laboratorio Materiales y método}

La preparación de muestras para el análisis morfológico siguió estándares convencionales para la observación en microscopio biológico (con escala micrométrica calibrada). Para este nuevo análisis, se sometieron a cortes delgados a las fibras que componen cada muestra (n 20), a efectos de seleccionar los campos de observación. Se fijaron en glutaraldehído al $2 \%$ en buffer de fosfato, se posfijaron en tetróxido de osmio al $1 \%$ y se incluyeron en resina Epon. A posteriori se efectuaron cortes ultrafinos de 60 nanómetros $(\mathrm{nm})$ los cuales fueron realizados con un ultramicrótomo Supernova Reichert-J y montados en grillas de cobre. Se contrastaron con acetato de uranilo y citrato de plomo y se examinaron en un microscopio electrónico de transmisión (MET) JEM 1200 EX II, según información brindada por el Servicio Central de Microscopia Electrónica de la Facultad de Ciencias Veterinarias de la UNLP.

\section{Resultados}

El primer comentario que podemos efectuar, refiere a la posibilidad técnica de realizar este tipo de estudios con material arqueológico. Se ha observado en todas las etapas del protocolo que las fibras arqueológicas resisten los procedimientos estándares de tinción y corte necesarios para la observación. Este hecho es de suma importancia por cuanto viabiliza la ampliación de la muestra a futuro. El único inconveniente reportado es el rasgado de material al momento del corte ultrafino, por tal motivo los técnicos informan sobre el reemplazo de la cuchilla de vidrio por una cuchilla de diamante. No obstante el reemplazo se pueden observar en algunas muestras la permanencia del rasgado, situación que no ha impedido alcanzar una correcta visión del campo a observar.

Los resultados obtenidos a través del examen en MET para los 2 grupos de muestras, dan cuenta una disposición diferente de las células corticales para cada uno de los respectivos grupos. Los mismos son coincidentes con las disposiciones mencionadas para camélidos silvestres y domésticos en la bibliografía citada. Asimismo al contar con las designaciones taxonómicas realizadas vía análisis morfológico, se ha podido evaluar la congruencia entre ambos tipos de análisis.

Para la muestra final seleccionada de CS1 (n9) (Figura 2), se observa la presencia tanto de orthocortex como de paracortex, con disposición bilateral definida (Figura 3), coincidente con los datos bibliográficos disponibles para camélidos silvestres.

Para la muestra final seleccionada de QS3 (n12) (Figura 4), se observa la presencia tanto de orthocortex como de paracortex, pero sin disposición definida, y mayor presencia de residuos nucleares (Figura 5), situación congruente con los datos bibliográficos disponibles para llama.

\section{Avance y conclusiones}

En función de los objetivos generales y específicos aquí enunciados, se considera de utilidad el resultado de la prueba realizada. El hecho de poder distinguir en camélidos entre vicuña/ guanaco y llama/ eventualmente patrón llama a partir del tipo y disposición de las células corticales, reviste sumo interés. Asimismo, nos da la posibilidad de confirmar de modo independiente las designaciones ya efectuadas, proporcionando más peso a los resultados obtenidos vía morfología de fibras. Sobre todo en el caso de aquellas muestras que fueron identificadas como patrón llama temprano, en contextos en los cuales la muestra ósea confirma solo la presencia de especies silvestres. Finalmente, el resultado no cierra la puerta a una evaluación positiva en relación a considerar la corteza como una variable crítica para la discriminación interespecífica, no solo para el caso de camélidos sino de otras especies. 


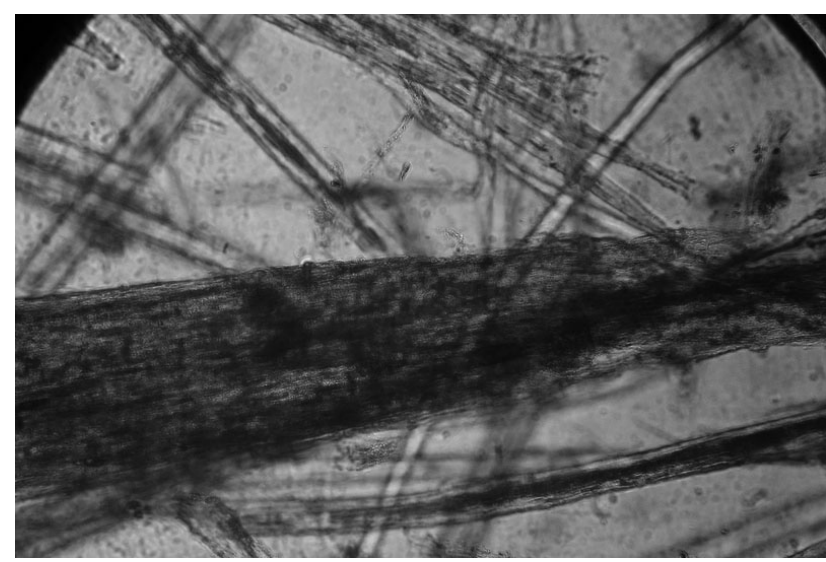

Figura 2- CS1 - 400X / Figure 2. CS1 - 400x

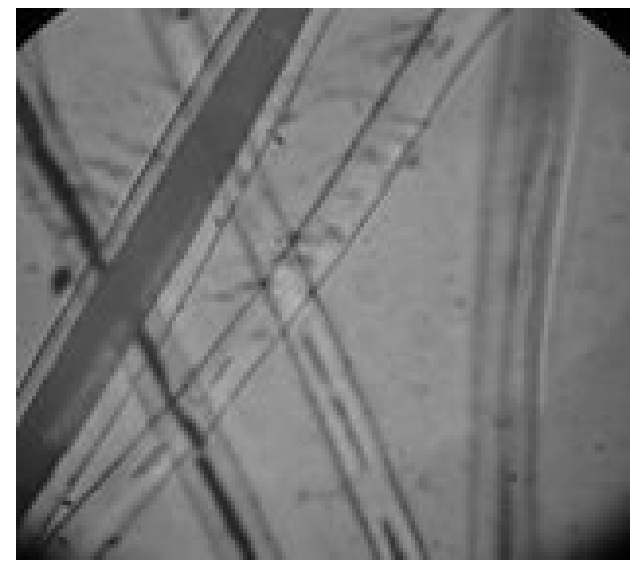

Figura 4. QS3- 400X / Figure 4. QS3- 400X

\section{Agenda}

En vista de los resultados obtenidos, se prevee en primer término, someter al análisis descripto un número mayor de muestras arqueológicas ya identificadas morfológicamente, para establecer definitivamente la potencialidad del mismo. En segundo orden, implementar la prueba sobre una muestra actual de cérvidos a fines de detectar si la via presentada permite detectar patrones que ayuden a ajustar la taxonomía a nivel de especie, considerando que no se observan diferencias en parámetros correspondientes a grosor, médula e índice de medulación, que solapan en las especies correspondientes a estos ungulados también presentes en el área de estudio.

\section{Agradecimientos}

Especialmente a Carlos Aschero, Mariana Mondini y Elizabeth Pintar. A los técnicos, Roxana Peralta y Fernanda Faisal, del Servicio Central de Microscopia Electrónica de la Facultad de Veterinaria de la Universidad Nacional de La Plata. A la Secretaría de Ciencia y Técnica de la Univ. Nacional de Jujuy y al Instituto de Biología de la Altura.

\section{Bibliografía}

Aschero, C, L. Manzi y G. Gómez 1993- 94. Producción lítica y uso del espacio en el nivel 2b4 de Quebrada Seca

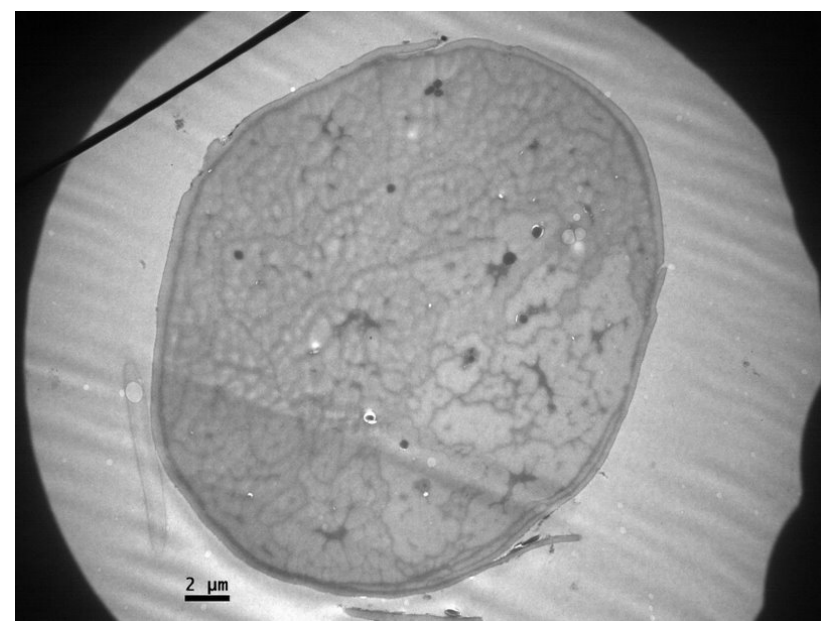

Figura 3. QS3- 6000X / Figure 3. QS3- 6000X

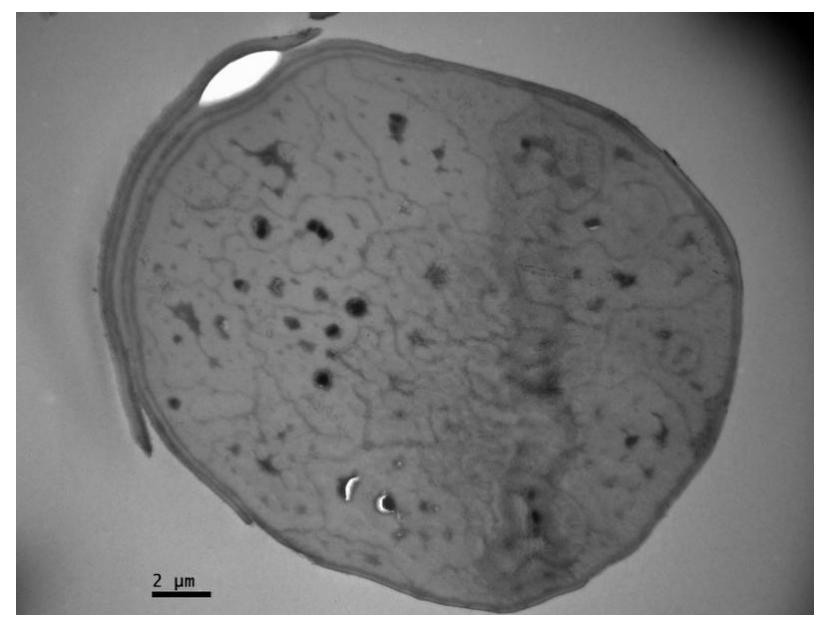

Figura 5. QS3- 8000X / Figure 5. QS3- 8000X

3. Relaciones de la Sociedad Argentina de Antropología XIX: 191- 214.

Carpio M. 1991. Aspectos tecnológicos de la fibra de los camélidos Andinos. Producción de rumiantes menores: Alpacas. Editado por C. Novoa y A. Flores, pp. 297-359. Lima.

Elkin, D. 1996. Arqueozoología de Quebrada Seca 3: Indicadores de subsistencia humana temprana en la Puna Meridional argentina. Tesis de Doctorado. Facultad de Filosofía y Letras. Universidad de Buenos Aires, Buenos Aires.

Frank, E. y S. Amuchástegui 1993 Estudio de la variación del diámetro dentro del vellón y entre animales en camélidos sudamericanos domésticos. Actas VII CIECS: 43- 50 .

Fraser, R., T. Macrae y G. Rogers. 1972. Keratins their composition, structure and Biosíntesis. Charles. C. Thomas, Illinois III. USA.

Hocsman, S. 2002. ¿Cazadores- recolectores complejos en 
la puna Meridional Argentina? Entrelazando evidencias del registro arqueológico de la microregión de Antofagasta de la Sierra (Catamarca). Relaciones de la Sociedad Argentina de Antropología XXVII: 193- 214.

Martínez, J., M. Mondini, E. Pintar y M. C. Reigadas 2010. Cazadores-recolectores tempranos de la Puna Merdidional Argentina: avances en su estudio en Antofagasta de la Sierra (Pleistoceno final-Holoceno temprano/medio). En J. R. Bárcena y H. Chiavazza (eds.), Arqueología Argentina en el Bicentenario de la Revolución de Mayo. XVII Congreso Nacional de Arqueología Argentina: 16911696. Mendoza, FFyL UNCU-INCIHUSA CONICET.

Mengoni, G. Y H. Yacobaccio. 2006. The Domestication of South American Camelids. A view from the SouthCentral Andes. Documentig domestication. New genetic and archaeological paradigms. Editado por Melinda A. Zeder, Daniel G. Bradley, Eve Emshwiller y Bruce D. Smith, pp. 228- 244. University of California Press.

Mondini, M. 2003. Formación del registro arqueofaunístico en abrigos rocosos de la Puna argentina. Tafonomía de carnívoros. Tesis de Doctorado. Facultad de Filosofía y Letras. Universidad de Buenos Aires, Buenos Aires.

Mondini, M. y D. Elkin. 2006. Cazadores-recolectores de la cuenca de Antofagasta de la Sierra (Puna Meridional Argentina): una perspectiva zooarqueológica y tafonómica. Cazadores y Recolectores del Cono Sur. Revista de Arqueología 1: 67-79.

Mondini, M., M. C. Reigadas, E. Pintar y J. G. Martínez 2011. Cazadores-recolectores de Antofagasta de la Sierra en el Holoceno medio. Poblaciones humanas y ambientes en el noroeste argentino durante el holoceno medio (ed. por M. Mondini, J. G. Martínez, H. J. Muscio y M. B. Marconetto), pp. 77-81. Taller de Arqueología, Córdoba.

Olivera, D. y D. Elkin. 1994. De cazadores y pastores: el proceso de domesticación de Camélidos en la Puna Meridional Argentina. Zooarqueología de Camélidos 1. Editado por GZC, pp. 95- 124.

Olivera, D. y S. Vigliani 2000- 2002 Proceso cultural, uso del espacio y producción agrícola en la puna meridional argentina. Cuadernos del instituto de Antropología y Pensamiento Latinoamericano 19: 459- 481.

Pintar, E. L 1996. Prehistoric Holocene Adaptations to the SALT Puna of Northwest Argentina. PhD Dissertation Southern Methodist University. Dallas.

Pintar, E. L. 2004. Cueva Salamanca 1: ocupaciones altitermales en la Puna sur (Catamarca). Relaciones de la Sociedad Argentina de Antropología XXIX: 349- 356.

Pintar, E. L. 2008. High-altitude deserts: hunter-gatherers from the salt puna of Northwest Argentina. International
Journal of South American Archaeology 2: 47 - 55.

Pintar, E. L. 2011. Obsidian sourcing and mobility strategies in a high elevation desert in NW Argentina. Trabajo presentado en el 76 Meeting de la Society for American Archaeology. Sacramento, California, EEUU.

Reigadas, M. C. 1992. La punta del ovillo. Determinación de domesticación y pastoreo a partir del análisis microscópico de fibras y folículos pilosos de camélidos. Arqueología 2: 9- 52.

Reigadas, M. C. 2001. Variabilidad y cambio cultural en el NOA desde los comienzos de la domesticación animal hasta la consolidación de las adaptaciones pastoriles. Tesis de Doctorado, Facultad de Filosofía y Letras, Buenos Aires, Biblioteca de la Facultad de Filosofía y Letras, UBA. Reigadas, M. C. 2006. Análisis de fibras animales para la definición de su status en el proceso de intensificación en la relación hombre- recurso animal: caso Quebrada Seca 3. Rev. Cazadores- recolectores del Cono Sur $N^{\circ}$ 1: $113-126$.

Reigadas, M. C. 2008 Explotación de recursos animales y producción textil durante el Holoceno (Antofagasta de la Sierra, Catamarca, Argentina). Estudios Atacameños No 35 : 35- 49.

Reigadas M. C. y M. Mondini 2010. Holocene huntergatherers in the Puna. Integrating zooarchaeological evidence in Antofagasta de la Sierra (Argentina). Trabajo presentado en el 11th ICAZ Conference, Paris.In BoneCommons, Item \#1484

Tchilinguirian, P., D. E. Olivera y L. Grana (2007). Paleoambientes sedimentarios y su aplicación en arqueología. Antofagasta de la Sierra, Catamarca. Metodologías Científicas Aplicadas al Estudio de los Bienes Culturales (ed. por d. Adrián Pifferetti y Raúl Bolmaro), pp. 472-482. Primer Congreso Argentino de Arqueometría, Rosario

Tucker, D. J., Hudson, A. H. F., Ozolins, G. C. Rivett, D. E. and Jones, L. N. 1988 The Chemical Composition of Specialty Animal Fibres, with Particular Reference to Cashmere. Proc. First Inter. Symp. on Specialty Animal Fibres, T1: 71-103. Aachen, Deutsche Wollforschunginstitut.

Tucker, D. J., A. H. F. Hudson, D. E. Rivett and R. I. Logan. 1990. The Chemistry of Specialty Animal Fibres, Proc. Second Inter. Symp. on Speciality Animal Fibers, T1: 1- 19. Aachen, Deutsche Wollforschungsinstitut.

Vázquez, D, P. Perovic y A. de Olsen. 2000. Patrones cuticulares y medulares de pelos de mamíferos del noroeste argentino (Carnivora y Artiodactyla). Mastozoología Neotropical. Journal of Neotropical Mammalogy, (2):131147. 